\title{
THE AIR AND WATER OF LONDON : ARE THEY DETERIORATING?
}

By Louis C. Parkes, M.D., D.P.H.Lond.Univ., Lecturer on Public Health at St. George's Hospital, Medical Officer of Health and Public Analyst for Chelsea.

\section{Read at a Sessional Meeting, March 9th, 1892.}

From time to time, to those who are of a reflective turn of mind, and more especially to Medical Officers of Health who are so intimately acruainted with Public Health questions, the question suggests itself-is London a better place to live in, as regards health and comfort, than it was half a century or so ago? Those who are acquainted with the past and present conditions of life of the mass of the population, would answer largely in the affirmative, but nevertheless with certain reservations. There can be no question that the majority of the population is far better housed now than at any previous time in the history of London. Slums and rookeries have to a considerable extent disappeared ; improved houses, and workingclass dwellings of substantial character have been erected; streets have been widened; open spaces lave been secured; and all classes have benefited enormously by the growth of practical sanitary knowledge in drainage, house sanitary arrangements, and sewerage. $\AA$ public health service, on the whole of a very efficient kind, has grown up in London, and sanitation is now enforced in a way which 50 years ago would have appeared almost incredible.

Vast improvements, then, have been effected; and we see the results of the improvements in a lowered general death-rate, and in a greatly diminished morality from small-pox, scarlet fever, typhus, typhoid fever, and diarrhna-diseases of the zymotic class usually said to be preventable. For instance, during the five years, 1886-90, the death-rate from small-pos in London was only one per million, as against 402 per million in 1841-50; during the ten years, 1881-90, the cleath-rate from scarlet-fever was 333 per million as against 1133 per million in 1861-70; during the same decennium the death-rate from 
fever (typhus, enteric, and continued fever), was 205 per million as against 979 per million in 1841-50; and the deathrate from diarrhœa in $1881-90$ was 749 per million as against 1030 per million in 1851-60. Virulent cholera has been practically extinguished during the past 20 years in London and in the country generally.

It is true that sanitary improvements have had little or no effect in lowermg the mortality from measles and whooping cough-these being rliseases of early childhood, over which it is extremely difficult to exercise any effectual public control. It is also true that diphtheria has shown a notable increase, and caused a heavy mortality in London during the past ten years, the death-rate for $1881-90$ being 259 per million, as against only 122 per million in the preceding decennium, but this is no doubt the price we have to pay for our system of compulsory elementary education, which causes the aggregation of such large numbers of children in confined spaces.

During the past two years, also, influenza has been with us, and has raised the death-rate by some 2,000 per million during its visitations. We can at present only plead want of knowledge of how to exercise control orer this disease in its epidemic form. It is certain that the ordinary methods of notification, isolation, and disinfection are-even if they were put in force-powerless to arrest the spread of the epidemic. They have not been put in force up to the present, however; and we are forced to be content with a policy of inactivity, whilst we watch the ravages of a communicable malady, a policy which furnishes a curious commentary on the limitations of human knowledge at the end of the nineteenth century.

With all its modern sanitary improvements, however, one, if not two, of the most vital factors of life in London, is undergoing steady, continuous degeneration. I allude to the air of London, and in a less degree to the water of London.

The degeneration of the air is due to the continuous growth of the town, which year by year removes the centre of the city further and further away from the country, and to the steady increase of smoke from coal fires poured into the atmosphere. It is a curious and interesting fact that London is dependent, one might say, almost for its life, upon the winds which bring pure air to it from the country. It is very seldom that the atmosphere in this climate is positively stagnant. Up aloft, above the chimney tops, there is usually, even on the calmest days, a just perceptible current, which serves to carry away the smoke and vitiated air, and brings fresh air in its place. When, however, during anticyclonic conditions, the atmosphere is positively stagnant, London, in winter, creates an atmosphere which is 
positively irrespirable. I need hardly remind you of the week's fog just before Christmas last, nor describe in detail what you all probably experienced.

Nor is this fog to be wondered at when we consider that there are some 800,000 houses in London, each with half a dozen or more chimneys in communication with an open fireplace: that some seven million tons of coal are burnt annually in the metropolis, or some 20,000 tons a day-on a cold winter's day as much as 40,000 tons is said to be consumed--of which daily quantity 200 tons will escape into the air as fine carbon or soot, with probably an equal amount of sulphur as sulphurous acid. There will be also produced about 60,000 tons of carbonic acid to help vitiate the air. The latter, being a gas, would escape easily and diffuse with the fresl air were it not for the suspended sooty particles in the fog; and thus it is easy to understand that the air of a yellow London fog may contain 12 or 14 volumes of this gas in 10,000 parts, as against the normal 4 per 10,000. The evil is bad enough, but it is increasing. Erery year some 15,000 or 16,000 new houses are added to London's huge bulk, each burning its due proportion of coal, and the number of foggy clays in a year is gradually increasing.

The mortality and illness produced by a dense yellow fog in London is not difficult to demonstrate. For instance, the death-rate of London for the fortnight ending December 19th, 1891, when ordinary atmospheric conditions prevailed, was only 18 per 1,000 . The great fog commenced on the $20 \mathrm{th}$, and lasted until night time on the 25 th. The death-rate of London for the fortnight ending January $2 \mathrm{nd}, 1892$, was 32 per 1,000 , or 14 per thousand in excess of the previous fortnight, and the aggregate mortality from cliseases of the respiratory organs in the fortnight exceeded the corrected average by 829. As a matter of fact, the excessive death-rate was very largely due to lung diseases brought on or aggravated by the condition of the atinosphere in Cliristmas week. Little, if any, part of this heavy mortality can be attributed to influenza, as this disease did not become widely epiclemic in London until after the first week in January; but the subsequent high death-rates in London, which then prevailed until the middle of February, are no doubt chiefly due to influenza mortality; although it may well be that the Christmas week fog prepared the way, so to speak, for the influenza, and weakened the defences of the body at the very time when it was most important that they should be at their strongest. At any rate, the epidemic through which London has passed has been far and away more fatal in its effects than either of its predecessors. 
Fogs, however, are but exaggerated types of what London air is during all the winter months. They concentrate public attention for a time, but are soon forgotten, like all other experiences which are painful to remember. The smoke, normally present in winter in our atmosphere, cuts off a good deal of light, as witness the "duration of sunshine" records in London and in the country outside of London. Ozone is practically absent from the air of London, and the carbonic acid, even of the most open spaces, is usually about 0.5 per 10,000 parts in excess of that in country air. It is difficult to say what exactly are the effects of the deteriorated atmosphere on the health of Londoners; but I think it may safely be assumed that much of the anœmia, which is so characteristic of London citizens-the pale faces, and disordered digestionsand many of the wasting diseases of children, more especially rickets and scrofula, are to no small extent due to a condition of atmosphere which prevents the perfect action of the lungs, and the complete oxygenation of the blood, and so lowers the tone of the body and the ability to repel the invasion of clisease. There is also the irritant effect of the dust and soot particles breathed into the lungs and deposited in the bronchial glands. These foreign particles are not obviously injurious to the majority of people, but they may affect some. In any case they do no good.

We must next consider what remedy, if any, there is for this evil, affecting, as it does, a population of four and a half million people, and increasing, as it does, in magnitude year by year. Many people are inclined to look on London fogs as natural phenomena inherent to London's site and climate, and therefore incapable of remedy. But this is a grand mistake. White mists are, no doubt, inseparable concomitants, under certain atmospheric conditions, of low lying positions on tidal rivers not far away from the sea; but yellow fogs are the products of coal combustion mixed up with nature's white mists, the latter being of a comparatively harmless kind, and limited more or less to night-time, as they are rapidly dispersed by the sun's rays.

It is now generally acknowledged that at least 95 per cent. of the smoke in London issues from the chimneys of dwellinghouses, the other 5 per cent. being "manufacturing" smoke. Consequently any attempt to deal with the smoke nuisance must aim at controlling the methods of combustion adopted by the householder. The manufacturer is already within the law; but the chimneys of private dwelling-houses may pour out as much black smoke as they can, with impunity. I am not an expert in this matter, and $I$ have brought this subject forward more with the view of giving an opportunity to those Fellows, 
Members, or Associates of The Sanitary Institute, who are well and practically acquainted with methods of heating and of smoke prevention to express their opinions than to air my own views. After the discussion it may be possible to formulate some resolution which will carry the sense of the meeting, and will show the public the lines upon which The Sanitary Institute is of opinion that the question of smoke abatement in London should be approached.

I will, however, propound the following as being questions to be discussed, and if possible decided one way or another.

(1) Is it reasonable to hope that the voluntary adoption in old houses, or the compulsory enforcement in new houses of smoke preventing stoves designed to burn ordinary domestic house coal, will visibly and satisfactorily abate the smoke nuisance in the metropolis?

(2) Can the use of anthracite or other smokeless coal be made compulsory throughout London, to the exclusion of ordinary house coal, having regard to the fact that such coal is not well suited to burn in ordinary domestic open fire-places, and that the present output is said to be at present only some 4,000 tons a day-London alone requiring on an average at least 20,000 tons a day?

(3) Is it possible to adopt, and render acceptable to the bulk of the ratepayers, a system (municipal or by private enterprise), of heating houses by steam or hot water pipes?

(4) Is the remedy to be looked for in the municipalisation of the London gas undertakings, with the production of a cheap gas at 1s. or 1s. tid. per 1000 cubic feet? For at this figure gas could be used for heating purposes as cheaply as coal at 20 s. per ton, equal heating effects being produced in dwellingrooms by open gas fires of good design, as by coal fires.

With reference to this latter question, subsidiary questions arise as to whether (a) it will be necessary to supply a gas free from illuminants, to be used for heating and cooking purposes only; and (b) to manufacture the gas in the colliery districts at the pit's mouth, and supply it to London through enormous mains under graduated pressure; in order that the price may be so low as to allow gas to compete successfully against coal.

I have said nothing as to the adoption of systems of slow combustion close stoves in houses, heated by colse or smokeless coal, as it appears to me that our climate, our habits, and our customs do not admit of, and indeed are strongly opposed to the system, which answers, however, well enough in countries with very cold and prolonged winters, when the chills and draughts produced by open ventilating fire-places would be intolerable. It seems as if no system of heating could be adopted in this 
country, which does not preserve, more or less intact, the open hearth, the cheerful blaze or glow of incandescent particles, and the escape of a large quantity of heated air up a flue, constituting the ventilation.

All this is very much against any general adoption of hot water or steam heating in ordinary dwelling-houses; and as far as my own experience goes, smoke preventing stoves are only smoke preventing when properly managed, disobedience to instructions, or carelessness, usually meaning a production of smoke in considerable quantity. The choice seems therefore to lie between the compulsory use of smokeless coal; or the taking of such steps by the citizens, as a whole, as will secure the enormous cheapening of coal gas, aud then by placing a tax on all kinds of coal grates, or even upon smoke-producing coal itself, to render it more economical for everybody to burn coal gas as a fuel.

It is true that coal gas produces, for equal heating effect, as much carbonic and sulphurous acids as coal does, but the absence of the suspended carbon soot particles makes all the difference as regards yellow fog. Without the suspended sooty particles in the air to form a nucleus for the moisture, the gaseous products of combustion will be enabled to escape into and diffuse with enormous masses of fresh air, and the dark, black, acrid, suffocating, choking atmosphere, which constitutes the modem London fog, will become a thing of the past. This sounds, perhaps, very optimistic and improbable, but it is feasible to restore purity to the London air, if we only set about it the right way. That the results of abolishing smoke would be remunerative, and well worth the vast outlay needed in the first instance, is a statement of the truth of which I an firmly convinced.

As regards the water supply of London, I am afraid we are working within a vicious circle, as we are doing with our air. Year by year London increases in size and population. Year by year the towns and villages, and London suburbs in the Thames and Lee valleys, are increasing as rapidly. The water drawn from the Thames and Lee has consequently to supply an ever increasing population, and the limits will before long be reached, when the resources of these rivers as reservoirs of water, will be stretched to their uttermost.

As the villages and towns on the upper reaches of the rivers and their tributaries increase in size, there is a constantly increased tendency for larger quantities of the waste refuse of these communities to find their way into the streams and rivers which are the natural drainage beds of the localities. This tendency to increase in pollution can only be kept in check 
by the watchfulness and devotion to duty of River Conservators, and by increased effort on the part of the water companies in the filtration and purification of the water they supply.

One of the special drawbacks of the Thames and Lee water companies, is the compulsion they are under to take in water from the river, when it is in flood, owing to the insufficient capacity of their storage reservoirs. The turbid and foul water from the river in flood is most difficult to filter effectually, with the result that a coloured, turbid water, containing an undue amount of organic matter, is at such times supplied to the consumers in London. This happened notably last autumn, when, owing to the continuous heavy rains, the Thames was in flood for a very long period, and the water supplied by a great majority of the Thames water companies to London was distinctly much inferior to the average quality. Who can say how much illness and loss of health was attributable to that wholesale depreciation in quality of our water supply?

It will not be amiss to turn to the Reports of the Official Water Examiner to see for ourselves what was the quality of the water supplied to London in 1891.

"At the end of January," writes the Water Examiner, "a practical illustration occurred of the incapacity of the existing works for dealing with the excessively turbid water which the Thames ocasionally affords. The breaking up of the prolonged frost, and the rainfall of the 29th January, produced a flood in the river of exceptionally muddy and polluted water. The filters having already suffered in condition from the great diffculty experienced in cleaning them when covered with ice, were overtaxed by the turbid water which was mavoidably admitted, and the supply delivered into London on the 30th January, and for some succeeding days was much discoloured." Dr. Frankland reported in February that the water abstracted by the Thames companies was, in all cases, of very inferior quality, being polluted by an abnormal amount of vegetable organic matter. That of the Grand Junction Company, supplied to over half a million of people, on the 5th February, surpassed, in respect of organic impurity, any sample of Thames water examined during the past 25 years. It was opalescent from imperfect filtration, and was not in a fit state for dietetic use.

After a time the water appears to have regained its average standard of purity, but in September we find it again reported that the water abstracted from the Thames suffered considerable deterioration in consequence of the flooded state of the river. The supply of the Chelsea Company was least affected, this company having the largest storage capacity for unfiltered 
water, viz., $14 \cdot 1$ days supply, or more than double that of most of the other Thames companies.

In October we find that the water abstracted from the Thames by all the companies, except the Chelsea, was very seriously affected by heary floods. It was brownish in colour, and the organic matter in solution, although chiefly of vegetable origin, had been increased in amount to a rery objectionable extent. "It is evident," writes Dr. Frankland, "that these companies, with their present limited storage, are umable to avoid the delivery of polluted flood water."

In Norember the Thames water supply had generally improved, but it was then the turn of the Chelsen Company to fail; and the water supplied by this company, which was far the best in October, was the worst in November, and contained 73 per cent. more organic matter than that supplied by the Lambeth Company on the same day.

In December the Chelsea supply had improved, but that of the other Thames companies had again fallen back, the excessive floods in the Thames Valley continuing and rendering it " most difficult for the companies, who have but small storage at their command, to send out water fit for dietetic use." The water of the Sonthwark Company was, indeed, opalescent from finely suspended clay, which was not removed by subsidence or filtration.

From the above quotations it will be seen that during five months of the year 1891, the water supplied to London from the Thames was for the most part of inferior quality, and on several occasions for day's together' not fit for dietetic use, that is to say not safe to drink. The river Lee is also liable to flooding, and the water abstracted from its lower reaches by the East London Company exhibited fiuctuations in quality similar to those affecting the Thames. The only water supplies to the Metropolis that maintain a good standard of purity throughout the year are those of the New River Company from the upper reaches of the Lee, which are comparatively unaffected by floods, and the deep well-waters of the Kent, Colne Valley, and East London Companies, the latter being invariably clescribed as of excellent quality.

Of course it is open to any one to say, that the year 1891 was an exceptionally bad one for the water companies owing to the severity of the frost in the early part of the year, and the tremendous rainfall in the latter part of the year. This may be granted, but still I think we shall all agree that the water supply of London with its $4 \frac{1}{4}$ million of inhabitants ought to be independent of exceptional circumstances of all sorts. As a matter of public lealth it is not a wise policy, and it is certainly 
not a scientific proceeding, to take in grossly polluted waters, such as the Thames or Lee in floods are, and then endeavour to render them potable by storage and filtration through sand and gravel. The endeavour is not always a successful one, as I have shown from official reports, and surely at the end of the 19th century, the citizens of the wealthiest city in the world, have a right to ask that the water supplied to them for domestic purposes shall be, like Crasar's wife, above suspicion.

Major Lamorock Flower (London) said he was much interested in Dr. Parkes' remarks on smoke abatement, but he thought it would not be reasonable to make every one alter their stoves nor to institute a house inspection to see that proper stoves were in use. Some difficulty would arise in making the use of anthracite compulsory, and, moreover, if brought into general use, there would not be enough anthracite to supply the demand. Means had been found of reducing the smoke from bituminous coal by treating it chemically, but this did not find farour with the public on account of the trouble it involved. The suggested use of steam and gas for beating purposes wonld, he thought, never find firrour with the English public. With regard to the water question, it was absurd to talls of the Lee being dried-up. A considerable quantity is taken, but it still will find an additional 10,000,000 gallons daily. The pollution of rivers could be almost entirely prevented by proper inspection. In the Lee, for instance, the water at the intake of the water-companies is equal to the purity of the river at its source; but in the Thames the present procedure against offenders is too cumbersome. He believed that it would be proved that there is plenty of water in the Thames and Lee water-sbeds for the supply of London: and he thought the London County Council had gone mad on the idea that another source of supply must be found. It would be fifteen years before Welsh water could be brought into London, and in the meantime nothing or little would be done to improve the present source of supply.

Mr. Rogers FinL, M.Inst.C.E. (London), said he suggested some years ago that the use of smokeless fuel might have been encouraged by only remitting the "coal dues" on this lind of fieel, and leaving them on ordinary smolie-producing conl. The great difficulty in the question of smoke and fog is to convince people that it is necessary to deal with it. Ordinary Londoners think that they cannot help the fogs, and that after all fogs do not do much harm. "That this view is a mistaken one is shewn by the fact that directly after serious fogs there is a great increase in the deaths from diseases of the respiratory organs. It is no use saying you cannot deal with the fog; you must, if fogs make it impossible to live in London, and things certainly seemed to be tending that way. On the question of the water supply, he 
thought the comparative purity of the Lee was due to the fact that the whole valley, including the tributary streams, was under inspection. In the Thames only the main stream and ten miles up the tributaries were under inspection, and this was not sufficient, as a great deal of pollution was brought down by the higher portions of the tributaries. It would be a long while before London conld obtain its water supply from other sources, though it way be necessary eventually ; in the meantime the present sources of supply ought to be thoroughly inspected, and the supply made as good as possible. He could not agree that London could rely altogether on the Thames and the Lee for its water supply. The large amount of manured land in the water-shed of these rivers would always considerably add to the pollution. He thought that the whole question of the sources of supply should be dealt with in reference to the needs of the country at large. Dartmoor, Wales, the Lakes, and some areas in Derby, were practically free from pollution, and he thought that all available sources of supply ought to be mapped out and allotted to different districts. He moved that, "In the opinion of this meeting of Fellows, Members, and Associates, of The Sanitary Institute, Parliamentary permission should be withbeld from all large appropriations of water-bearing areas in Wales or elsewhere, until the Royal Commission on Sources of Water Supply about to be appointed has reported."

Mr.F. T. Pourson (Chelsea) seconded the resolution. He was glad that the Birmingham Water-bill should be the means of making London look to its water supply. There was no doubt that fogs caused a good deal of injury to child-life, and destroyed comfort. Gardening in London is a good indicator of the purity of the air.

Dr. H. R. Kenwood (London) said that with regard to the prevention of fog he thought that the adoption of coal-gas in place of coal was the most likely to be adopted, but the question arose as to what the injurious effect of fog is due to, and whether the burning of so much gas wonld prove an advantage to the public health. By the universal adoption of coal-gas for heating purposes we should certainly be spared the dark and dirt of our London fogs, but it is a question whether the very large amount of injurious gases which would escape into the atmosphere as products of coal-gas combustion, and whichunder those atmospheric conditions which give rise to fog-would be held down over the city to be respired, would not suffice to render the air just as injurious as it is under the present circumstances. He thought it might be possible to find some source of heat other than that of coal or coal-gas combustion.

Mr. S. C. G. FAIRCHILD (London) thought that a good deal of the pollution of the Thames in dry seasons was due to the house-boats on the river. He asked whetber it was a fact that water passed through crushed flints, absorbed silica, and prevented the water acting on lead-pipes. 
The Champrar (Sir Thomas Crawford) said he quite agreed with the resolution proposed by $\mathrm{Mr}$. Field with regard to the water-supply of London. He thought that the attention of the public had been principally directed to the surface water, but that we should also consider the water-bearing strata underlying the Thames and the Lee, where possibly we might find a great augmentation of our present supply. In most cases the sub-soil is a great store-house of water. If surface water is used, it is of great importance to secure gathering grounds free from impurities. With regard to fogs, he was particularly struck with the bealth aspect of the question, and he thought it would be very useful if every health officer would estimate the consequence of exposture to fogs, and suggested that the degeneration of Londoners might be due to fogs.

The resolution proposed by Mr. Rogers Freld was carried unanimously.

Moved by Dr. H. R. Kenwood and seconded by Mr. Coates, and carried unanimously, "That it is important in the interests of the public health that London fogs should be enquired into by a Royal Commission."

Dr. Lours Parkes (London) in reply said, no doubt the physique of Londoners was degenerating. With regard to the uselessness of inspecting only ten miles up tributary streams he instanced an outbreak of typhoid by which pollution was carried into the Wey and so to the Thames. 